Archivum, LXIX, 2019, pp. 313-341

\title{
Distanciamiento e identificación en la poesía latina de Juan Interián de Ayala
}

\author{
Marcos Ruiz SÁNCHez \\ UNIVERSIDAD DE MURCIA \\ marcosr@um.es \\ María Ruiz Sánchez \\ Universidad de Murcia \\ mrs4@um.es
}

Recibido: 20/11/2018

Aceptado: 29/03/2019

\section{RESUMEN:}

La concepción de la elegía como un género basado en los sentimientos da lugar en la poesía neolatina de mercedario español Interián de Ayala a una forma poética en la que la identificación se combina con el distanciamiento. El mismo fenómeno se produce igualmente en los epigramas del autor, en los que la influencia de Catulo se combina con la de Marcial y con una utilización de los símbolos poéticos profundamente original.

PALABRAS CLAVE: Juan Interián de Ayala, poesía neolatina, identificación, distanciamiento. 
Estrangement and identification in the Latin poetry of Juan Interián de Ayala

\begin{abstract}
:
The concept of the elegy as a genre based on feelings gives rise in the Neo-Latin poetry of the Spanish Mercedarian Juan Interián de Ayala to a poetic form in which identification is combined with estrangement. The very same phenomenon occur in the author's epigrams, in which the influence of Catullus is combined with that of Martial and with a use of the profoundly original poetical symbol.
\end{abstract}

KEY WORDS: Juan Interián de Ayala, Neo-Latin poetry, identification, estrangement.

\title{
1. Introducción
}

Juan Interián de Ayala (1656-1730) fue uno de los miembros fundadores de la Real Academia de la Lengua creada por iniciativa del Marqués de Villena. En esta institución colaboró de forma muy activa en la elaboración del primer Diccionario de autoridades. En su juventud ingresó en el Colegio de los Mercedarios de Alcalá de Henares. Estudió Filosofía, Teología y Lenguas Sagradas en Alcalá y Salamanca, universidad esta última en la que ocupó las cátedras de Artes, Elocuencia y Lenguas Sagradas. Fue nombrado Predicador y Teólogo de la Real Junta de la Concepción.

La obra poética de Interián, Humaniores atque amoeniores ad Musas excursus: siue Opuscula poetica quae quondam lusit aut pinxit R.A.P.M. Fr. Ioannes Interian de Ayala, editada en el año 1729 por su correligionario Francisco de Ribera, está organizada por géneros a la manera de los poemarios neolatinos de la época. Las composiciones en hexámetros (Heroica) van seguidas por las líricas, las elegías y finalmente por los epigramas, de acuerdo con una escala ideológica de los géneros, de más a menos valorado. El final de la obra contiene también algunos textos en castellano, versiones o imitaciones de autores latinos.

Los hexámetros incluyen poemas fúnebres sobre las exequias reales y guardan estrecha relación con su faceta de predicador; las composiciones líricas son fundamentalmente religiosas, las 
elegías son de temática no personal y entre los epigramas figuran poemas que responden a la tradición emblemática, como la serie dedicada a los Icones philosophorum, y poemas a imitación de Catulo y de Marcial ${ }^{1}$.

Un año después del poemario latino se publica a expensas de la Orden de la Merced el Pictor Christianus, obra destinada a corregir los errores que solían cometer los pintores en la realización de imágenes sagradas. Una segunda edición, ya en castellano, se publicó en 1782 .

Interián fue considerado ya en el siglo XVIII como un predecesor del nuevo gusto literario ${ }^{2}$. En él se ha visto un antecedente del Neoclasicismo y el representante de una tradición neoclásica y anti-barroca que habría convivido siempre con los excesos de la literatura española del XVII (Sebold, 1985).

Esta orientación de su obra va unida sin duda al trato frecuente con la poesía de los clásicos españoles del Renacimiento y con los autores latinos clásicos. Esta imagen del poeta está basada especialmente en su poesía en lengua castellana. El propósito de este trabajo es, sin embargo, poner de manifiesto cómo es a través del examen de su poesía neolatina, que constituye la mayor parte de su creación literaria, como mejor puede verse la faceta de hombre de su época del autor, al tiempo que su profunda originalidad.

Nos centraremos para ello en dos de los géneros cultivados por el autor, la elegía y el epigrama. La obra latina de Interián muestra una determinada concepción de estos dos géneros, que no coincide totalmente con la dominante en otras épocas, como pretendemos demostrar con el examen de algunas de dichas composiciones.

1 Sobre la poesía lírica de Interián y la presencia de la iconografía y los emblemas en su obra puede verse Ruiz Sánchez y Ruiz Sánchez (2018 y 2019).

2 Juan Sempere y Guarinos $(1785,9)$ menciona a Interián de Ayala entre "los primeros que sembraron en España la semilla del buen gusto", junto a Martí, Costa, Montiano y Feijóo. Sobre la génesis del Neoclasicismo puede verse Mestre Sanchis (2002). 
Su poesía es, por otra parte, una creación profundamente personal, a pesar de explotar módulos y formas que pueden parecer convencionales dentro de la propia poesía neolatina. La concepción de la poesía de la época y las convicciones religiosas del autor favorecen una poética contenida, que rechaza como superficial el ornato poético y favorece los temas emblemáticos y la aparición de personajes animales, que aproximan sus composiciones a las fábulas tradicionales. Al mismo tiempo, el uso que Interián hace del símbolo supera los límites de la alegoría o del emblema, para convertirse en un espejo que facilita el examen espiritual por parte del lector y del propio poeta.

Estas características de la obra del autor evidencian la unidad de las distintas facetas de su producción. Su creación poética está estrechamente relacionada con el interés por lo simbólico que demuestra en su obra iconográfica y en su labor como predicador.

\section{Las elegías}

En las elegías de Interián subyace, sin duda, una concepción del género como poema relacionado con los sentimientos, especialmente el amor, la pena por la muerte y la ausencia. No parece tampoco carente de significado que las dos primeras elegías, Petrus lacrimans y Planctus Magdalenae non inuento in sepulchro corpore Iesu (Ribera, 1729, 53-62), estén dedicadas a figuras arquetípicas del arrepentimiento como san Pedro y María Magdalena. Significativamente el poema sobre Pedro concluye con el recuerdo de Magdalena ${ }^{3}$.

En estos dos primeros poemas el texto se presenta como un monólogo. En ambos el personaje que habla se dirige a Jesucristo, ya muerto, con lo que en cierto modo enlazan con la concepción de la elegía como género relacionado por excelencia con la

3 Las elegías sobre el arrepentimiento encuentran su equivalente en las composiciones poéticas escolares de la época y en los poemas de los autores neolatinos que les sirven de modelo, como los recogidos, por ejemplo, en la Bibliotheca Rhetorum de Le Jay $(1725,704-708)$. 
poesía fúnebre. Abunda también en este sentido el término planctus del título.

Así, la elegía tiene el carácter de un poema sobre sentimientos, especialmente, de acuerdo con la tradición, vinculados con la muerte y con el amor. Hay que recordar, con todo, que en esta época la poesía se sigue entendiendo como mímesis, si bien en el caso de la elegía se trataría de imitación de los sentimientos. De este modo la diferencia entre la temática personal y la objetiva tiene menos importancia y la elegía se aproxima de forma natural a la heroida ${ }^{4}$.

El comienzo del poema sobre Magdalena juega con el tópico de la semejanza entre los efectos del amor y la muerte. Magdalena misma, al haber perdido al amado, es equiparada al sepulcro abandonado. La desaparición del cadáver renueva el sentimiento de ausencia, a pesar de que es en realidad signo de la resurrección. El resto del poema sigue desarrollando esta paradoja y ambigüedad simbólica.

La imagen de la cierva herida, representación del alma enamorada, que conjuga al tiempo el amor y la muerte, va unida a la de la fuente purificadora, que indica transformación y renovación ${ }^{5}$. La ambigüedad se confirma en el siguiente símil, el del heliotropo, de carácter emblemático, que expresa la dependencia amorosa. También actúa como símbolo de renacimiento y metamorfosis, pues el sol que muere, renace, como Cristo ha de renacer de la tumba, a pesar de que eso sea aún ignorado por la Magdalena del monólogo. Enlaza, por otra parte, con el término lux, que con el valor de 'luz' y de 'vida' utiliza la hablante para referirse a Jesucristo a lo largo de todo el poema. Magdalena se convierte así en claro símbolo, como la esposa del Cantar bíblico, del alma humana en añoranza de la unión con el amado (Ribera, 1729, 61, vv. 39-52):

4 Recuérdese que en esta época la heroida se entiende como "epístola heroica", concepción más amplia que la del modelo ovidiano original. De este modo, podía denominarse así a toda epístola elegíaca puesta en boca de un personaje célebre.

5 Sobre el tópico de la cierva herida, en que se conjugan fuentes bíblicas y clásicas, puede verse Lida de Malkiel (1975, 52-79). 
Vulnere facta celer gelidos petit incita fontes, Currit et impatiens saucia cerua sitis.

Sed fruitur gaudens optato gurgite; uenis

Vita redit, puris dum refouetur aquis.

Non ego, quae aethereas sitiens contingere lymphas,

Fons animae (heu!), Iesu, tu mihi uerus abes.

Versa etiam in florem sequitur uaga lumina semper

Nympha olim (ah!) nimium cognita, Phoebe, tibi.

Sed tenet; et uitam, quam se dum condidit umbris

Perdiderat, rursus sole oriente capit.

Ast ego nil coelos iamiam, nil sidera curo.

Sole magis, Iesu, qui mihi charus eras.

Ipse ueni. Aut saltem diuis concedito plantis,

Affixa ut moriar; lux mea solque, redi.

Urgida por la herida busca ágil las heladas fuentes y corre incapaz de soportar la sed la cierva herida. Pero al fin goza del agua anhelada; la vida vuelve a sus venas, mientras se restablece con las aguas puras. No me ocurre igual a mí, que me veo consumida por la sed de alcanzar las celestes aguas, pero a quien faltas tú, Jesús, fuente verdadera de mi alma. Incluso transformada en flor sigue siempre tus luminarias girando la ninfa en otro tiempo, jay!, demasiado conocida por ti, Febo. Pero las posee; y de la vida, que había perdido al sepultarse en las sombras, disfruta de nuevo con la salida del sol. Pero yo nada me cuido ya de cielos ni de astros. Tú eras más querido para mí, Jesús, que el sol. Ven tú mismo, en persona. O concédeme al menos que muera hincada de rodillas ante tus divinas plantas; vuelve, luz y sol míos.

El uso de las imágenes muestra claramente otra de las características de la poesía del autor, la conexión con la emblemática y el símbolo, algo que se pondrá de manifiesto todavía más en los epigramas, que con frecuencia adoptan el aspecto de auténticos emblemas.

La elegía siguiente, Ad nobilem iuuenem petentem libros Ouidii de Amoribus, et Arte (Ribera, 1729, 62-64), muestra los límites de la conexión que la elegía como género tiene con la temática 
amorosa. Parte de la idea, propia de la literatura moralizante, del peligro que subyace a los placeres. El poema adquiere una implicación mucho mayor si lo leemos como contrapartida de la elegía sobre Magdalena, en la que se habla del amor divino.

En el mismo poema la navegación de Ulises, Circe y las sirenas, como encarnación de los peligros del amor equivocado, formaba parte desde antiguo de la interpretación alegórica de la mitología y de los emblemas (vv. 3-10) ${ }^{6}$.

También la imagen de la mariposa atraída por el fuego y consumida al fin por él, aunque de origen petrarquista, estaba integrada ya en la tradición emblemática (vv. 19-26)

Cernis ut exiguus deceptus imagine pulcri

$$
\text { Ales, nocturnam circuit orbe facem? }
$$

Credulus, impatiensque, nouos sibi quaeritat ignes, Et circum innumeras itque reditque uices.

Nec mora nec requies: flammae quoque uellicat alas

Vis uaga, non rebus parcere docta suis.

Vritur, et caeca tandem caligine mersus,

Damnat adorati luminis obsequia.

¿Ves cómo el exiguo insecto alado, engañado por la imagen de la belleza, gira en torno al nocturno fuego? Crédulo e impaciente, busca para sí nuevos fuegos, y va y viene alrededor innumerables veces. No hay demora ni descanso: la fuerza sin rumbo de la llama arranca sus alas, incapaz de respetar lo que le pertenece. Se abrasa $\mathrm{y}$, abrumada al fin por la ciega oscuridad, condena su complacencia por la adorada luz.

6 En el emblema CXV (Sirenes) de Alciato $(2016,126)$. Cf. Conti $(1988,539)$, Pérez de Moya (1995, 212-218) y Brumble (1998, 312-315).

7 Manero Sorolla identifica los sonetos XIX (Son animali al mondo de si altera...) y CXLI (Come talora al caldo tempo sòle...) del Canzoniere de Petrarca como fuente de numerosos poemas sobre el tópico en Italia y España (1990, 313-317). Sobre el tópico de la mariposa consumida por el fuego en la literatura española pueden verse los estudios de Cabello Porras (1990 y 1991), Pulido (1999) y Pedrosa (2003). 
La imagen de la mariposa atraída por el fuego fatal y el mito de Orfeo evocado más tarde (vv. 37-40) invierten las imágenes de renovación y resurrección del poema anterior. El mito de Orfeo se convierte en el de una resurrección imposible (v. 40): Reddita iam uitae, morte perempta noua est, "devuelta ya a la vida pereció por nueva muerte"s.

El tema del poema Ad amicum epistola (Ribera, 1729, 64-67) pertenece a la misma constelación de motivos. La reacción del poeta ante el texto que le ha enviado el amigo corresponde a los tradicionales síntomas de amor. La obra se confunde con los autores clásicos. Y los poetas citados forman el canon de la elegía amorosa (vv. 13-16):

Fallor? an extremis Naso reuocatus ab umbris

Doctas Romana mittit ab urbe notas?

Castos an aliquis scripsit Propertius ignes?

Musane uel resonat, docte Tibulle, tua?

¿Me engaño? ¿Acaso vuelto a la vida desde las sombras del más allá, Nasón envía sus doctos escritos desde la ciudad de Roma? ¿O algún Propercio escribió sobre amores castos? ¿O es que resuena, docto Tibulo, tu Musa?

La aparente contraposición entre la poesía y la labor del filósofo se obvia a través de la doctrina de la inspiración y las alusiones a los coliambos de Persio y a Hesiodo (vv. 23-32):

8 El eco del episodio virgiliano de Orfeo está presente igualmente en la poesía fúnebre de Interián. El motivo del ruiseñor, procedente de las Geórgicas de Virgilio (IV 511-515) y tradicional en la literatura española (Lida de Malkiel, 1975, 100-117) es utilizado por el autor (Ribera, 1729, 6-7) en el poema dedicado a María Luisa de Orleans (vv. 11-26). Al ruiseñor añade Interián en este caso la tórtola, que resulta apropiada al contexto matrimonial. La relación con la obra virgiliana y con el mito de Orfeo queda clara con la frase Te ueniente die, te decedente canebat, que constituye una clara reminiscencia de las Geórgicas (IV 466). Otro eco virgiliano es el tibi lilia plena / exspargam manibus (vv. 65-66), que retoma los versos manibus date lilia plenis / purpureos spargam flores de la Eneida (VI 883-884). 
Quisnam igitur te (nam quid non uereamur amantes?)

Compositis docuit fundere uerba sonis?

Quis dedit, ut tantum, quem percensebat amicus

Theiologum, Musae tam uideare Philos?

Quis tibi tam blandus concessit somnia Phoebus,

Somnia, queis uates efficit ille suos?

Scilicet obscuri Satyrarum carminis author

Haec data de coelo pernegat esse sibi.

Ascraeus sed iure senex sibi missa fatetur,

Ingenio factus nocte poeta suo.

¿Quién, así pues (porque ¿qué es lo que no hemos de temer los amantes?), te enseñó a derramar palabras con artificiosos sonidos? ¿Quién te concedió que tú, a quien tu amigo contaba entre los teólogos, parezcas tan amigo de la Musa? ¿Qué Febo tan blando te concedió sueños, sueños con los que hace que sus poetas lleguen a serlo? Es verdad que el autor de la oscura poesía de las sátiras niega rotundamente que estos sueños le sean inspirados desde el cielo. Mas el anciano de Ascra con más razón confiesa que le han sido enviados, convertido en poeta de noche por su ingenio.

Otra parte de las elegías del autor está formada por composiciones que él mismo denomina lusus elegiaci. En estas elegías lúdicas tienen un gran protagonismo los animales, lo que recuerda la poesía burlesca tradicional y la fábula. Adoptan habitualmente la forma de un monólogo puesto en boca del personaje principal $^{9}$. Algo similar ocurre con frecuencia, como veremos, en los epigramas del autor.

En estas elegías lúdicas el texto se suele cerrar con la comparación entre el personaje animal y el ser humano al que está des-

9 Una excepción es la del pájaro enjaulado, Passer in cauea (Ribera, 1729, 76-77), en la que en lugar de un monólogo se trata de un diálogo. La situación recuerda la fábula del ratón de campo y el de ciudad, pero en este caso los papeles están invertidos, pues el pájaro enjaulado conoce bien las incomodidades de su condición, mientras que el libre está seducido por el atractivo aparente de la situación del otro, con lo que el texto concluye con la invitación a cambiar los papeles. 
tinada la enseñanza. Así, en Canis uenaticus (Ribera, 1729, 73-76) la muerte del perro de caza da lugar a una moraleja referente a las vidas de los hombres perdidas inútilmente en la guerra.

La comparación con el mito lleva a la parodia en el caso de la historia del enano y la grulla, Nani, siue Pygmaei gruis ab se interfectae praeclara uictoria (Ribera, 1729, 70-73), que evoca en la mente del lector el tema de la lucha entre grullas y pigmeos, a la que se hace referencia al final del texto. El poema adquiere desde el principio un tono burlesco, con un final en el que de nuevo encontramos humorísticamente la comparación con el lector.

En Asinus ad speculum (Ribera, 1729, 78-79) la situación es análoga al posible comienzo de una fábula. El asno, encarnación de la estupidez, ante el espejo, símbolo del conócete a ti mismo, como ejemplo de imposible autoconsciencia. También aquí se hacen abundantes alusiones al mito (Midas y sus orejas de asno y Sileno). El término fabula, que el autor utiliza en los versos 27-28 (Plura loquor, quae prisca tamen uix fabula claudat: Stultitiae siquidem est fabula quisque suae), está a medio camino entre el sentido de 'mito' y el de 'fábula'. La comparación con el ser humano se refiere en este caso específicamente a la poesía y al rechazo de los temas habituales de la poesía profana.

La forma de monólogo propia de casi todas las elegías del autor, tanto serias como lúdicas, debe ponerse en relación con la concepción del género. Hay que recordar que en esta época la elegía se entiende como la mímesis de un sentimiento. Incluso la lírica, salvo la religiosa, se entendía como mimética. Esto explica la frecuencia del monólogo. Las excepciones son la Ad amicum epistola y la elegía final, Senectutis descriptio (Ribera, 1729, 79-82). El tema de la vejez es tradicional de la elegía desde Maximiano. El principal aliciente es aquí el repaso desengañado de la vida al final del poema. Al mismo tiempo la concepción moral de la literatura, que domina toda la obra del autor, hace de esta el reflejo del propio poeta e implica una exigencia de veracidad ${ }^{10}$.

10 La idea de la obra poética como reflejo del autor y del tema está expresada de forma especialmente clara en el poema lírico de Interián titulado In laudem uitae D. 


\section{Endecasílabos}

El último bloque del poemario de Interián está dedicado a la poesía epigramática. El primer apartado de esta sección viene dado por los endecasílabos falecios. El modelo evidente es en este caso Catulo. El propio editor observa que la métrica es la de Catulo, no la de Marcial ${ }^{11}$. Catulo estaba considerado desde el Renacimiento como el modelo de los endecasílabos, mientras que en los epigramas propiamente dichos la cuestión del canon estuvo siempre abierta, si bien el siglo anterior había supuesto el triunfo en la práctica de Marcial sobre el poeta de Verona.

El estilo de estas composiciones de Interián es el característico "estilo catuliano", invención de la literatura neolatina, basada en la reiteración de rasgos formales y temáticos asociados con la poesía de Catulo y con la cualidad de la suauitas o uenustas, rasgos que apelaban al mundo de los sentidos y de los sentimientos ${ }^{12}$.

Propios del "estilo catuliano" son, por ejemplo, en cuanto a la forma, la composición anular con el primer verso repetido al final, que parece identificado en la mente del autor con este metro y con Catulo, los frecuentes diminutivos, las repeticiones, los comparativos, las comparaciones estereotipadas, etc.

Petri Paschasii, uersibus elegiacis editae a R.P.F. Michaele de Vlate (Ribera, 1729, 52-53). La exigencia de veracidad y el rechazo del artificio es el núcleo del poema In museolo (Ribera, 1729, 51).

11 Versus phaleucos hendecasyllabos (in quo metri genere uisus est author regnare non paucis neque ineruditis lectoribus) ea semper lege composuit, quam Catullianam uocare possumus: ut nempe primus quisque pes non tantum spondeus (ut praecipiunt uulgares magistri) sed uel trochaeus etiam esse possit aut iambus: qua lege non ita frequenter utitur, ut factitauit ipse Catullus, quod facile patebit inspicienti (Ribera, 1729, 82).

12 Con respecto al "estilo catuliano" y sus implicaciones puede verse Ruiz Sánchez (2018). Tales temas conllevan igualmente sus opuestos. Este tipo de temática justifica, por ejemplo, el poema sobre el chocolate de Interián titulado In laudem potionis chocolaticae (Ribera, 1729, 96-98) o el dedicado a la gota (Ribera, 1729, 101-103). También se explica así la presencia de este estilo en el poema sobre el martirio de Nicetas (Ribera, 1729, 96-91), con su mezcla de sadismo y voluptuosidad. 
El estilo catuliano constituía de este modo en la literatura humanística, frente al estilo de Marcial, basado en el ingenio, un polo opuesto que remitía al mundo de las sensaciones y de los sentimientos, que justificaban los excesos del lenguaje poético. Ahora bien, conviene tener en cuenta que la propia concepción de los endecasílabos de la primera parte del liber catuliano como epigramas, propia de la interpretación de la poesía del autor de Verona desde el Renacimiento y que contrasta con la visión actual de tales poemas como composiciones líricas, muestra claramente la huella del papel de mediador que cumplió inicialmente Marcial en la recepción de Catulo en la literatura europea moderna ${ }^{13}$.

Así pues, no podemos extrañarnos ni del papel que juega Catulo en la poesía epigramática de Interián, ni de que esta influencia sea inseparable de la de Marcial.

El "estilo catuliano" parece suponer una especie de polo en la poesía de Interián, marcado por la identificación con el tema, que puede rozar incluso la ingenuidad. El énfasis en los sentidos y en los sentimientos de este tipo de poesía viene así a justificar cierto desvío de las exigencias éticas, fundamentadas en la religión, que le llevan a cuestionar los excesos del lenguaje literario cuando dan la espalda a la realidad.

Las dos primeras composiciones de este estilo están dedicadas al niño Jesús. La temática y la actitud de ternura hacia Jesús niño justifican, pues, la forma. Además del estilo hay ecos claros de la poesía del de Verona. Así, en el primer poema titulado In Domini circumcisionem (Ribera, 1729, 82-85), Flendo turgidulis rubens ocellis (v. 10) evoca claramente el c. 3 de Catulo (v. 18).

La circuncisión de Cristo y su planteamiento como prefiguración de la crucifixión era, por otra parte, tema trillado del epigrama neolatino, tanto en endecasílabos como en dísticos ${ }^{14}$.

13 Sobre la recepción de Catulo y su contraposición a Marcial en la literatura moderna pueden consultarse Gaisser (1993), Swann (1994) y Ruiz Sánchez (2018).

14 La circuncisión de Cristo era tema frecuente del epigrama neolatino. Cf., por ejemplo, Remond, II,17, De quibusdam Poëseos studiosis, qui de cultro quo Christus Domi- 
La presencia de Marcial junto a Catulo se hace visible en el poema siguiente, Ad puerum Iesum (Ribera, 1729, 85-86), en el que las repeticiones del comienzo constituyen una singularísima imitación, como auténtica versión a lo divino, del poema de Marcial sobre Issa: Iesu stelliferi decor Parentis, / Iesu uirgineae corona Matris; / Iesu Rex superi potens Olympi, etc. (vv. 1-9). El texto de Marcial (I 109) constituía un ejemplo clásico de la cualidad de la uenustas o suauitas en los tratados sobre el epigrama ${ }^{15}$.

La misma inseparabilidad de Catulo y Marcial como modelos se encuentra en el poema Tranquillae ac beatae uitae monita (Ribera, 1729, 92-96). Los dos primeros versos, que se repiten en anillo una vez más al final del poema, contienen ya un eco catuliano: $S i$ tristes animi leuare curas, / Et tecum studeas libens morari. En efecto et tristis animi leuare curas es verso catuliano (c. 2, v. 10). Pero el tema corresponde a los consejos para la vida feliz en Marcial (X 47), tantas veces imitados en la literatura moderna.

Dentro de los consejos figura también el tipo de versos que se pueden escribir y las lecturas recomendables (vv. 102-107):

Versus scribere, non Catullianos,

Vel quos improba perlegat Lycoris,

Sed quos uel pueri legant pudici

Intonsi, iuuenesque, uirginesque, 105

Cordatusque senex legat, probari

Qui demum sobrio queant Catoni.

Escribir versos no catulianos o destinados a ser leídos por la desvergonzada Licoris, sino que puedan leer incluso los púdicos muchachos imberbes y los jóvenes y las doncellas, y que pueda leer el viejo sensato y que, por último, puedan ser aprobados incluso por el sobrio Catón.

nus circuncisus est, aemulo carmine scripserunt, non satis apposite $(1623,32)$ y Alois, II, 16, In Pueri Iesu Circumcisionem (1646, 230).

15 Por ejemplo, en el tratado de Mercier sobre el epigrama $(1653,90)$ 
El tema corresponde a la polémica en torno a la legitimidad del uso de la obscenidad y del erotismo en literatura, común en poesía a partir del Renacimiento y que tiene su origen en el c. 16 de Catulo. Sin embargo, las expresiones y el planteamiento son claramente de Marcial (la referencia al público, la improba Lycoris y los iuuenes uirginesque, así como la mención de Catón ${ }^{16}$. Naturalmente Interián, a pesar de la imitación, invierte la postura de Catulo y Marcial, quienes defienden la separación entre el estilo y el hombre.

\section{Epigramas en dísticos}

En los epigramas en dísticos el modelo indiscutible es Marcial. Hay, por otra parte, huellas importantes de otras fuentes de inspiración.

Un componente esencial viene dado en este caso por el elemento iconográfico y emblemático. Los elogios de santos que formaban parte de esta sección fueron incluidos también en la edición del Pictor Christianus (1730). Los Icones philosophorum, epigramas que glosan las figuras de filósofos griegos (Ribera, $1729,127-136)$, dan fe de la importancia de este componente en la obra del autor. Algunos de los epigramas de Interián pueden ser calificados de emblemas, como ocurre, por ejemplo, con la serie dedicada a cuatro tipos de relojes (Ribera, 1729, 154-156).

La mezcla de tradiciones diferentes en los epigramas puede verse en los dos dedicados a la mariposa ahogada en el agua que llevan por título Papilio aqua mersus (Ribera, 1729, 138):

Quae uaga sollicitis circumdare lumina gyris, Assueta et fato nobiliore frui,

16 Interián funde diversos pasajes de Marcial. En el epigrama III 69 se dirige Marcial a un escritor rival que solo compone poemas destinados pueris uirginibusque. Los de Marcial esperan como público a jóvenes libertinos, muchachas fáciles y viejos verdes. Catón aparece en un epigrama de Marcial entrando en el teatro solo para salirse (I Pról.). Cf. para los límites temáticos del género epigramático Ruiz Sánchez (2018, 1053-1062). 
En liquido hic uolucris absorpta est gurgite, qualis

Nec secus altiuolans Icarus amne fuit.

Nomina, neu dubita, moriens quin fecerit undis.

Iam merito hae, merso papilione, tument.

El alado insecto, que acostumbraba a rodear sin rumbo con solícitos giros las luminarias y morir de muerte más noble, se ha ahogado en líquido torbellino, no de otra forma como por volar demasiado alto lo fue en las aguas Ícaro. No dudes que al morir dio nombre a las ondas. Con razón se hinchan de orgullo estas, por haberse ahogado en ellas una mariposa.

Alatus tremulis uermis dum quaeritat ignem

Flexibus, ignoto gurgite mersus adest, Laetus et in uitreo tumulari marmore, "quantum

Haec, ait, obsequium praestitit unda mihi!

Vnus nempe meae famae non sufficit ignis;

Fataque demersum nobiliora manent. Linquat odoratum uolucris Titania nidum;

Plus erit, hic gelidis si moriatur aquis".

El alado gusano mientras revolotea buscando con solicitud el fuego se ha hundido en un abismo de agua por él desconocido $y$, alegre de ser sepultado en el vítreo mármol de las aguas, dice: “QQué gran servicio me han prestado las olas! A mi fama no basta solo el fuego; una muerte más noble me espera al morir ahogado. Deje el ave Fénix ${ }^{17}$ su perfumado nido; más famoso será, si muere aquí por heladas aguas".

La expresión fato nobiliore del v. 2 del primer epigrama alude claramente a Marcial ${ }^{18}$. Es evidente que estos poemas remiten

17 Un elemento emblemático más. Titania avis es el "ave del sol" o "renacida con el sol", porque, según la leyenda, era transportada tras morir hasta el altar del sol o porque renacía tras ser consumida por los rayos del sol.

18 XI 69, 12. Fato nobiliore mori / tegi era, con todo, un cliché de la poesía neolatina ya totalmente desvinculado del original en Marcial y frecuente en la literatura emblemática. Por ejemplo, en una obra titulada Succinta descripción de las exequias, que a su 
a los dedicados por el poeta latino a animales sepultados en el ámbar: abeja (IV 32), víbora (IV 59) y hormiga (VI 15). El animal insignificante se convierte en joya tras su muerte. Pero las implicaciones simbólicas son diferentes. La mariposa muerta constituye una alegoría de la atracción de lo que está más allá de los propios límites. En el primero de los dos epigramas se evoca el mito de Ícaro, también perteneciente a la tradición emblemática. Como Ícaro, la mariposa, por volar demasiado cerca del fuego, acaba cayendo al agua. La similitud da lugar a un distanciamiento irónico, como encontramos en ocasiones similares en la equiparación de lo grande y lo pequeño en los epigramas griegos.

El segundo epigrama refleja en espejo el primero. La relación temática se aprecia en las reminiscencias verbales; el v. 2 del uno (fato nobiliore frui) encuentra un eco en el v. 6 del otro (Fataque... nobiliora). Como en el anterior se comparan las dos formas de muerte, la del fuego, tema tradicional en la literatura, y la del agua. Si en el primer texto se equiparaba su destino al de Ícaro, ahora se compara con otro emblema de lo sublime, el Fénix, que muere para renacer en su abrasado nido. La perífrasis alatus... uermis del verso inicial subraya, por una parte, la insignificancia del insecto, pero también llama la atención hacia la metamorfosis, destino que el insecto comparte con el exótico Fénix.

Más próximo al tema tradicional, procedente de Marcial, está el epigrama siguiente, Apis melle immortua (Ribera, 1729, 159):

Dum labor egregius, dum mella liquentia fingo,

Fabricor atque nouos nocte dieque fauos,

Dulcia pone meas tenuere ligamina plantas,

Muneribusque statim sum tumulata meis.

Ne mea, mortales, doleatis fata; quis istam

Reina Doña Maria Luisa de Borbón, consagró el Regio Tribunal de la Contratación de Las Indias de esta ciudad de Sevilla, el día primero de abril del año de 1689, un autor anónimo cierra con este cliché un epigrama latino de ocho versos en que se compara la corona real y los lirios de la casa real de Francia con la corona de espinas (1689, s.p.): Nil mirum, uepres cupiunt mea haec lilia, namque / non possunt fato nobiliore mori. 
Non fortunatam computet esse uicem?

Plangite uos alios, quibus otia, funeris instar;

Me iuuat ingenio sic periisse meo.

Mientras, labor egregia, modelo la miel que destila y fabrico noche y día nuevos panales, dulces ataduras retuvieron mis plantas y al punto fui sepultada por mis dones. No lamentéis mi muerte, mortales; ¿quién no pensaría que se trata de una suerte afortunada? Llorad por otros, para los que el ocio equivale a la muerte; a mí me agrada haber perecido así a causa de mi ingenio.

También aquí se integran, sin embargo, elementos procedentes de géneros diferentes. El tema claramente se relaciona con los epigramas de Marcial sobre la abeja (IV 32) o la hormiga en el ámbar (VI 15). Abejas y hormigas son símbolos tradicionales de laboriosidad. Pero en este caso el texto adopta la forma de monólogo. Puede así entenderse como un epigrama demostrativo, un emblema o un epigrama fúnebre. En todos estos casos es normal el uso de la ficción elocutiva en primera persona. La petición al lector de que no llore por el difunto es un tópico consolatorio del epigrama fúnebre. Epigramas fúnebres de animales formaban parte de la tradición epigramática alejandrina. El final es el equivalente del lema de un emblema. Una frase como ingenio meo perii podría fácilmente actuar como tal.

El protagonismo que tienen en estos epigramas los personajes animales los relaciona con las fábulas. Como fábula auténtica puede considerarse de hecho el siguiente texto, Apologus elegans ex Ferdinando Pulgario (Ribera, 1729, 161):

Hortata est asinum uulpes, ut protinus aulam

Pergat, ubi inueniat sorte uel arte locum.

Cui asinus: “Quid stulta mones? namque ocius ipse

Ridebor, meritis bellua digna iocis".

At uulpes infit: "In me tua cura recumbat;

Hinc tibi nil timeas; i modo, perge cito.

Nam si te insolitus celsis fauor inferat astris, 
Vt careas sequitur cognitione tui;

Sin secus, et uiles asinus reuoceris ad artes,

Non iam qui tete nouerit ullus erit".

La zorra aconsejó al asno que inmediatamente se dirigiera a la corte, para labrarse por suerte o por arte una posición. Le respondió el asno: “Qué me aconsejas, estúpida? Enseguida se reirán de mí, bestia digna de merecidas chanzas". La zorra le responde: "Sobre mí recaiga tu preocupación; por eso no temas; adelante, no te pares. Pues si un insólito favor te transporta a lo más alto, la consecuencia será que no te conozcas a ti mismo; si, por el contrario, como asno, eres devuelto a tus viles artes, no habrá nadie ya que te conozca".

El autor ha transformado en realidad profundamente la historia. El relato de Hernando del Pulgar está en los Claros varones de Castilla narrado como exemplum (1789, 256-258). Los animales mayores, celosos del favor de que goza el raposo, aconsejan al león que lo envíe a conseguir los sesos y el corazón del asno, único remedio que garantiza la salud del león. El zorro convence a un asno para que vaya a la corte, pero el animal, acogido en principio amablemente, huye cuando ve al león adoptar un aspecto más feroz. El zorro trata de convencerlo de nuevo para que regrese:

E1 raposo (...) fué al asno, é preguntóle por qué se avía venido. E1 asno le respondió: anda, vete, amigo, con tu corte; no querría el placer de su favor por la tristeza que sentí en el disfavor. Dixo el raposo: ¡cómo eres ignorante! Sabete que en las cortes con el favor no te conoscerás, é con el disfavor no te conoscerán.

La historia se repite y solo en el tercer intento acaba el león por matar al asno. Pero cuando busca el corazón y los sesos no los encuentra, pues el zorro los ha robado, argumentando ante las preguntas del león que el asno no tenía tales partes en su cuerpo. ¿Cómo podría el animal tener seso y corazón si tres ve- 
ces volvió a la corte llevado por la codicia y por ganar hacienda perdió la vida?

Aunque sea un cuento de animales, es bastante diferente de una fábula clásica. La historia de los consejeros maliciosos que convencen al poderoso para que envíe al héroe a una misión y la repetición de la misma en tres ocasiones es propia de los cuentos populares. Es un motivo que sirve para reiterar funciones narrativas y relatos enteros. Se encuentra tanto en las narraciones de animales como en los cuentos maravillosos. Interián ha reducido las distintas ocasiones a una sola aproximando así el relato a la fábula clásica. También es común que la historia acabe con el triunfo del héroe y el perjuicio del personaje que lo envía, en este caso el león. El tema del cor cerui, por lo demás, formaba parte del acervo tanto de la fábula grecolatina como de los cuentos populares. Como ocurre frecuentemente en el cuento de animales y en la fábula esópica, se trata de la historia de un engaño: del asno seducido por el zorro, pero también del propio león que al final es burlado por el raposo.

Interián ha prescindido de este marco narrativo para centrarse en el encuentro entre el asno y el zorro: un elemento que nos aproxima a la fábula clásica y a un género como la sátira.

El enfrentamiento entre dos animales es recurso característico también de la fábula. Igualmente es frecuente que uno de los dos pronuncie la agudeza final que constituye el cierre temático de la historia. Los personajes representan no solo dos formas de entender la vida. El blanco del componente satírico es la propia vida en la corte, lo que era, por otra parte, el núcleo principal de la enseñanza del exemplum original. Los recelos del asno, que teme precisamente ser el blanco de la sátira y del castigo social de la risa, son retorcidos retóricamente por el zorro que, negando lo dicho por el asno, confirma en el fondo una visión mucho peor de la vida en la corte.

La diferencia entre estos epigramas relativos a animales y la fábula se manifiesta, por ejemplo, en el poema Agnus ad lanionem, "El cordero al carnicero" (Ribera, 1729, 159): 
Nil queror. Innocua haec, lanio saeuissime, nullo

Simplicitas gemitu nouit acerba pati.

Viuere sed poteram, matrique patrique superstes.

Supplicat hoc uotis impia turba Deos;

Quae tamen imbelles auertit ab ubere natos,

Ventribus ut fiant funera grata suis.

Stultorum lacrimas ridebunt fata parentum.

Hoc uestrae, dicent, nos docuere manus.

No me quejo. Esta inocente sencillez sabe sufrir, crudelísimo carnicero, las amarguras sin ningún gemido. Pero podía vivir y sobrevivir a mi madre y a mi padre. Esto lo suplica la impía muchedumbre a los dioses; la misma que, sin embargo, aparta a los pacíficos hijos de la ubre, para que se conviertan en cadáveres gratos a sus vientres. Los hados se reirán de las lágrimas de los estúpidos padres. Esto, dirán, nos lo enseñaron vuestras manos.

El efecto es, sin embargo, diferente del de la fábula. En la fábula la acción ha de ser única, mientras que en este caso se trata de una situación habitual. Los animales como personajes implican siempre un marco de acción, un proyecto narrativo. Es cierto que en la tradición emblemática encontramos integradas en ocasiones desde Alciato auténticas fábulas. Pero en el emblema no es necesario que la acción sea única.

El uso de animales tenía en la fábula la finalidad, según Lessing, de evitar la identificación del lector con el personaje ${ }^{19}$. Pero es evidente que esto no ocurre en la fábula poética moderna. El cordero de nuestro texto es por sí mismo un símbolo de inocencia, como en la primera fábula de Fedro, la conocida fábula del lobo y el cordero, que versa sobre la injusticia. La actitud del narrador de las colecciones griegas, que cuenta la historia recogiéndola de la tradición y que se entromete muy poco en ella, contrasta con la postura de un autor como Fedro o los autores modernos de fábulas poéticas. Frente a la actitud editorialista de 
la fábula de las colecciones clásicas, los animales se convierten en símbolos que distan de impedir la identificación ${ }^{20}$.

En el poema de Interián la identificación resulta intencionadamente conflictiva; va unida a una distancia irónica, que no hace sino incrementarse en el sobresalto final, cuando descubrimos que no se trata de una simple queja sobre el mal en el mundo, del sufrimiento de los inocentes, sino de algo que nos concierne directamente.

Un reflejo de ese conflicto en cuanto a la identificación viene dado quizá por la reiteración en los epigramas del recurso del monólogo. En muchos de estos textos el hablante es uno de los personajes, generalmente el propio animal: el ratón atrapado en la ratonera, el loro que se dirige a su dueña, la hormiga alada que se queja de su destino, el pez cogido por el anzuelo, la abeja muerta por culpa de la propia miel, el cordero degollado por el carnicero, el cabritillo que se encuentra en la misma situación o el ratón con el que el gato juega. El cierre del texto pone de manifiesto habitualmente la relación con el mundo de los hombres. Así, en el epigrama titulado Mus, cum quo felis lusitat (Ribera, $1729,165)$, el ratón con el que juega el gato se dirige a este diciéndole que deje la crueldad para sus amos: Linque nefas dominis crudelibus, improbe qui ipsos / Cum quibus assuescunt ludere, saepe necant (vv. 9-10), “Deja el crimen para tus crueles dueños, malvado, que suelen matar a los mismos con los que acostumbran a jugar".

En otras ocasiones inversamente es el animal el interpelado. Así, la perdiz convertida en reclamo (Ribera, 1729, 143) o el ruiseñor al que el goloso pretende devorar (Ribera, 1729, 151). También en este caso el desarrollo del texto sigue los mismos derroteros. Por ejemplo, en el epigrama In perdicem destinatam aucupio, aparece de nuevo el tema del hombre como maestro del mal: Non aliter lautas poteras effugere mensas, I Istis ni inciperes artibus esse no-

20 Mientras que Lessing criticaba por esta razón a los autores modernos, Vigotski (1972) en su fundamental ensayo sobre el género ve inversamente en este hecho uno de los elementos definitorios de la fábula poética moderna. 
cens (vv. 7-8), “No de otro modo podías escapar de las suntuosas mesas, si no empezaras a ser dañina mediante tales artes".

La fábula tradicional gira en torno al engaño: un animal se engaña a sí mismo o es engañado por otro. El error es castigado, a menos que se rectifique a tiempo. El distanciamiento va unido a la actitud didáctica. La víctima se queja allí de su error, que lo ha conducido a la desgracia. Aquí, se da tanto la identificación como el distanciamiento, y los engañados somos nosotros mismos, los lectores. Al igual que en la sátira, la voz del ingenuo, del extranjero o, como en este caso, del animal nos hace percibir la realidad que nos pasaba inadvertida.

Esa incomprensión de nuestros propios actos está plasmada en el epigrama Agnus ad lanionem en la expresión metonímica de la agudeza con que concluye, equivalente del cierre final de una fábula o del lema de un emblema: uestrae nos docuere manus. No dice "nos habéis enseñado vosotros mismos a ser crueles", sino "vuestras manos nos enseñaron".

El epigrama siguiente sobre el cabritillo (Haedus ad eundem) constituye una especie de duplicación del anterior, cambiando el personaje del cordero por el del cabritillo (Ribera, 1729, 160). Ambos textos tienen además el mismo número de versos y las quejas de los dos animales siguen caminos similares. El epigrama aprovecha el tema tradicional del macho cabrío que es sacrificado a Baco por haber dañado las hojas de la vid ( $A P$ IX 75 y 99). Pero en el epigrama griego el interpelado es el animal adulto. Aquí, en cambio, se trata una vez más del monólogo del animal sacrificado. El humor es, sin embargo, mucho más evidente, profundizando la dualidad de identificación y distanciamiento. El tema recibe así una nueva vuelta de tuerca. La relación paródica muestra que el mal no es algo que exista independientemente de nosotros, al tiempo que pone de manifiesto su trivialidad.

Interesante desde el punto de vista literario resulta el epigrama titulado Gulosus ad lusciniam (Ribera, 1729, 151): 
Lapsa iaces. Teneo te, hospes gratissima siluis, Gratior hinc nostro sarcina facta coco. Lapsa iaces tandem putri circumdata uisco. Implebis nostram praeda canora famem. Experiar num sis uolucris iucunda palato

Tam bene, quam bibulis auribus esse soles.

Quid tamen hoc? equidem tenuis sine corpore uita, Plumaque non huius pondera uocis habens.

Quam similis multis quibus est facundia, mensque,

Garrula uox, nugae, praetereaque nihil!

Has caído. Te tengo, huésped gratísimo a los bosques, convertido en trabajo más grato para nuestro cocinero. Caíste al fin apresada por la trampa de liga. Colmarás, botín canoro, nuestra hambre. Pondré a prueba si eres ave tan agradable para el paladar como sueles serlo para nuestros sedientos oídos. ¿Qué es, con todo, esto? En verdad tenue vida sin cuerpo, pluma que carece del peso que corresponde a la voz. ¡Qué similar a muchos que poseen elocuencia e ingenio, charlatanería, bagatelas y, fuera de eso, nada!

Nuevamente encontramos la situación arquetípica del animal atrapado. Pero los papeles están invertidos desde el punto de vista elocutivo. Aquí no es el animal el que habla, sino el captor humano. El poema integra elementos epigramáticos, como la definición paradójica del ruiseñor, al igual que el eco de Ausonio, poeta bien conocido de Interián, como muestran las adaptaciones del final del poemario. El ruiseñor entre los árboles es apenas nada más que pura voz sin nada, música sin cuerpo.

Podríamos esperar un epigrama similar a los anteriores en los que el ruiseñor dirigiera sus quejas contra el cazador. ¿De qué le sirve dañar al alado músico? Poco provecho ha de obtener de quien es, como dice Lope de Vega en La Dorotea, apenas cítara de pluma (Acto IV, escena 3). No tiene alimento que ofrecer; en cambio, nos regala el don de su música.

Pero el autor ha elegido aquí la postura opuesta. Lapsa al comienzo del poema resalta esta caída de la altura poética a la 
cruda realidad. La poética identificación del ruiseñor con la incorpórea música se vuelve en su contra. En cierto modo puede leerse este poema como la actitud desilusionada y dolorosa ante el propio arte y también hacia los excesos de una poesía meramente formal y recargada. La agudeza final recuerda la de una fábula. Como la proverbial estatua que carecía de seso, el ruiseñor, pura voz, carece de toda sustancia. De todas formas, aunque pueda entenderse como texto dirigido contra la poesía y oratoria anteriores, la desilusión que manifiesta es más general, y forma parte de una postura vital que va más allá de lo estrictamente literario.

A pesar de la importancia de Marcial como modelo y de las alusiones esporádicas a los escritores satíricos latinos de época imperial, no son muchos los epigramas puramente satíricos en la obra de Interián. Un ejemplo imitado de Marcial es el titulado In Aulum (Ribera, 1729, 152). El tema del banquete indeseable y el mal servicio a los invitados de escasa importancia es típico de Marcial. La agudeza final recuerda también las del poeta romano ${ }^{21}$.

El molde esencial al que se ajustan todos los demás componentes de esta poesía es el emblema y el símbolo. Con frecuencia los epigramas de Interián constituyen auténticos emblemas, como el titulado Candela lanterna inclusa, "Candela encerrada en una linterna" (Ribera, 1729, 164). La presencia de lo emblemático se manifiesta también en los epigramas sobre animales, como el dedicado a la hormiga alada (Ribera, 1729, 153), cuyo monólogo concluye advirtiéndonos de no aspirar a ir más allá de nuestra condición, o el titulado Piscis hamo captus (Ribera, 1729, 157-158), en el que la conclusión (Res sibi nil similes hamus, amorque notant) refleja el tipo de juegos de palabras característicos de los emblemas.

21 Festis domi diebus, Aule, ieiuno (v. 26), «Los días festivos, Aulo, ayuno en casa». Un epigrama de Marcial (XI 35) sobre el invitado a un banquete que no conoce a nadie concluye diciendo que cena solo en casa. En otro poema de Marcial se afirma de alguien que nunca cena en casa, pues cuando no es invitado no cena (V 47). 
Este uso de los elementos emblemáticos ha contribuido a la contención poética del autor, a su renuncia a los adornos exteriores del lenguaje literario. Pero, al mismo tiempo, el uso del símbolo ha perdido la seguridad en la interpretación, propia de los emblemas tradicionales, que prometía la certeza de un lenguaje de la verdad más allá de la ambigüedad a la que nos condena la condición humana. Baste citar en este sentido un último epigrama de Interián que lleva por título Arbor enata in coemeterio, "Árbol nacido en el cementerio" (Ribera, 1729, 157):

Arbor amoena, uiden' sparsis ut frondibus ultro

Christiadum in mediis nata uiget tumulis?

Pompa, uiror, fastus res sunt contermina morti.

Sic uno regnant pompaque, morsque loco.

Spes nec uana datur tibi rursus ab arbore, mortis

Vt fias tandem uictor et ipse tuae.

Quidni etenim? foecundo iterum num puluere trunco

Vita redit, prorsus non reditura tibi?

Vos animae testes, quorum data membra sepulcris,

Iam iuuat in cineres nunc abiisse leues.

¿Ves cómo el hermoso árbol crece vigoroso, esparciendo espontáneamente sus ramas, a pesar de haber nacido en medio de las tumbas de los fieles? Pompa, verdor, orgullo son cosas vecinas a la muerte. Así, en un mismo lugar reinan la pompa y la muerte. $Y$ no es vana la esperanza que te hace concebir el árbol de convertirte en vencedor tú mismo de la muerte. ¿Por qué no? ¿Si vuelve la vida del polvo fecundo al tronco, no ha de volverte a ti? Testigos sois vosotras, almas, a cuyos miembros entregados a los sepulcros ya resulta agradable haberse convertido en ligeras cenizas.

El árbol actúa al tiempo como emblema de la vanidad de la vida y de la esperanza de resurrección. El texto puede, sin embargo, servir de ejemplo, de cómo Interián supera habitualmente el marco meramente emblemático. La visión del poeta se vuelve conflictiva y, por eso, más moderna. 


\section{Conclusiones}

Las elegías y los epigramas de Interián de Ayala comparten algunas características: la forma del monólogo, las composiciones dedicadas a animales, que con frecuencia hablan en primera persona, y la utilización de elementos emblemáticos. Por dispares que puedan parecer estos rasgos tienen una fuente común: la concepción de la poesía de la época y la raíz moral de la inspiración del poeta.

Los autores clásicos latinos están presentes de forma significativa en los textos de Interián, pero siempre mediatizados a través de las concepciones literarias contemporáneas. El poeta, de acuerdo con su condición religiosa, rechaza la temática amorosa de las elegías clásicas y la temática obscena del epigrama, oponiéndose en esto explícitamente a Catulo y a Marcial. Sin embargo, tanto en un caso como en otro reutiliza elementos de los autores clásicos dentro de una poesía moralizante.

De este modo las elegías de Interián presuponen una concepción del género basada en los sentimientos. Los temas del amor, el arrepentimiento, la añoranza y la muerte estarán así presentes en las elegías de temática sacra. La concepción de la elegía como imitación del sentimiento explica también la frecuencia de la ficción elocutiva del monólogo, y da lugar a una tensión entre identificación y distanciamiento que es característica de toda la obra de Interián.

Los epigramas del autor español se inspiran con frecuencia en Marcial y en los escritores satíricos latinos, pero la temática satírica propiamente dicha se diluye al carecer de todo componente de invectiva personal. De forma paralela los poemas de carácter no satírico inspirados en el autor latino se aproximan al emblema.

La exigencia moral le lleva a una búsqueda de la verdad poética, que le induce incluso a rechazar los excesos del lenguaje poético. De ahí también la importancia en su obra del símbolo, vehículo perfecto de la verdad que trasciende la debilidad humana. 
La orientación moralizante de la poesía del autor aproxima la elegía y el epigrama a la fábula, género con el que comparten la frecuente presencia de animales como personajes y la reflexión final, que relaciona el tema con el ser humano. Pero en la fábula clásica de las colecciones la temática animal servía para el distanciamiento del lector, propio de la finalidad didáctica del texto. El lector debe juzgar desapasionadamente para asimilar la lección de la fábula. La moral de la fábula griega es una moral dura, racional. En la obra de Interián, en cambio, el símbolo da lugar a la identificación, al igual que ocurre en la fábula poética moderna. La situación se convierte en un espejo de la existencia humana.

Del mismo modo los elementos iconográficos y emblemáticos escapan de la rigidez del puro mensaje alegórico para expresar de forma más profunda la realidad existencial del hombre.

\section{Bibliografía}

Alciat, A. (2016) Emblemata / Les Emblèmes, Fac-similé de l'édition lyonnaise Macé Bonhomme de 1551, Laurens, P. (trad.), Paris, Les Belles Lettres.

Alois, P. (1646) Petri Alois Neapolitani e Societate Iesu Epigrammatum Centuriae sex., Neapoli, sumptibus Iacobi Pierii.

Arcaz Pozo, J.L. (1989) "Catulo en la literatura española", Cuad. Filol. Clás. Estud. Lat., 22, 249-286.

Brumble, H. D. (1998) Classical Myths and Legends in the Middle Ages and Renaissance. A Dictionary of Allegorical Meanings, London-Chicago, Fitzroy Dearborn Publishers.

Cabello porras, G. (1990) "La mariposa en cenizas desatada: una imagen petrarquista en la lírica áurea, o el drama espiritual que se combate dentro de sí", Estudios Humanísticos, 12, 255-277.

CABello porras, G. (1991) “La mariposa en cenizas desatada: una imagen petrarquista en la lírica áurea, o el drama espiritual que se combate dentro de sí" (2aㅡ parte), Estudios Humanísticos, 13, 57-75.

Conti, N. (1988) Mitología, Iglesias Montiel, R. M.ํy Álvarez Morán, M. ․ C. (trad.), Murcia, Universidad de Murcia. 
Gaisser, J.H. (1993) Catullus and his Renaissance Readers, Oxford, Clarendon Press.

Interián de Ayala, J. (1730) Pictor Christianus eruditus. Siue de erroribus qui passim admittuntur circa pingendas, atque effingendas Sacras Imagines, Madrid, Typographia Conuentus praefati Ordinis.

Interián de Ayala, J. (1782) El Pintor Christiano y erudito, o tratado de los errores que suelen cometerse frequentemente en pintar, y esculpir las imágenes sagradas, Madrid, Joaquín Ibarra.

Le JAY, G.F. (1725) Bibliotheca Rhetorum, praecepta et exempla complectens, quae ad oratoriam et poeticam facultatem pertinent (auctore P.G.F. Le Jay, S.J.). Pars posterior, Parisiis, apud Gregorium Dupuis.

Lessing, G.E. (1825) Fables and Epigrams; with Essays on Fable and Epigram, London, J. \& H.L. Hunt.

Lida de Malkiel, M. ․ (1975) La tradición clásica en España, Barcelona, Ariel.

Manero Sorolla, M. P. (1990) Imágenes petrarquistas en la lírica española del Renacimiento. Repertorio, Barcelona, PPU.

Mercier, N. (1653) De conscribendo epigrammate, Parisiis, apud Ioannem de la Caille et Claudium Thibout.

Mestre Sanchis, A. (2002) “Juan Interián de Ayala, un humanista entre los fundadores de la Real Academia", Bulletin Hispanique, 104.1, 281-302.

Pedrosa, J.M. (2003) “La mariposa, el amor y el fuego: de Petrarca y Lope a Dostoievski y Argullol”, Criticón, 87-88-89, 649660.

Pérez de Moya, J. (1995) Philosofía secreta de la gentilidad, Clavería, C. (ed.), Madrid, Cátedra.

Pulgar, F. Del (1789) Claros varones de Castilla, y letras de Don Fernando del Pulgar, Madrid, por D. Gerónimo Ortega e hijos de Ibarra.

Pulido, I. (1999) "Fuentes clásicas de dos motivos de la poesía española: la grulla y la mariposa", Exemplaria, 3, 17-35. 
Remond, F. (1623) Francisci Remondi Diuionensis e Societate Iesu Carmina et orationes, Antuerpiae, ex officina Martini Nutii.

Ribera, F. De (1729) Humaniores atque amoeniores ad Musas excursus: siue Opuscula poetica quae quondam lusit aut pinxit R.A.P.M. Fr. Ioannes Interian de Ayala, Matriti, ex Typographia Conuentus praefati Ordinis.

Ruiz Sánchez, M. (2018) "Catulo ante la encrucijada de los géneros", Paideia, LXXIII, 1039-1062.

Ruiz Sánchez, M. y Ruiz Sánchez, M. (2018) “Elementos iconográficos y emblemáticos en los epigramas de Interián de Ayala", Imago. Revista de Emblemática y Cultura Visual, 10, 217-228.

Ruiz SÁnchez, M. y Ruiz Sánchez, M.a (2019) “Contención poética en la poesía lírica latina de Interián de Ayala", Liburna, 14, 377-389.

SEbold, R.P. (1985) "Interián de Ayala en el neoclasicismo español", en Studies in Eighteenth-Century Spanish literatura and Romanticism in Honour of John Clarkson Dowling, Newark, Delaware, Juan de la Cuesta, 151-165.

Sempere y Guarinos, J. (1785) Ensayo de una biblioteca española de los mejores escritores del reynado de Carlos III, T. I, Madrid, en la Imprenta Real.

Succinta descripción de las exequias, que a su Reina Doña María Luisa de Borbón, consagró el Regio Tribunal de la Contratación de Las Indias de esta ciudad de Sevilla, el día primero de abril del año de 1689 (1689), Sevilla, Juan Francisco de Blas.

Swann, B.W. (1994) Martial's Catullus. The Reception of an Epigrammatic Rival, Hildesheim-Zürich-New York, Olms, 82-154.

Vigotski, L.S. (1972) "Análisis de la fábula", en Psicología del arte, Barcelona, Barral, 119-152. 
